\title{
Effect of Nanometric Metallic Hydroxides on the Flame Retardant Properties of HDPE Composites
}

\author{
F. I. Beltrán-Ramírez, L. F. Ramos-deValle, \\ E. Ramírez-Vargas, S. Sánchez-Valdes, A. B. Espinoza-Martínez, \\ J. G. Martínez-Colunga, O. S. Rodríguez-Fernandez, \\ E. N. Cabrera-Alvarez, and M. L. López-Quintanilla
}

Centro de Investigación en Química Aplicada (CIQA), Boulevard Enrique Reyna 140, 25294 Saltillo, COAH, Mexico

Correspondence should be addressed to L. F. Ramos-deValle; luis.ramos@ciqa.edu.mx and E. Ramírez-Vargas; eduardo.ramirez@ciqa.edu.mx

Received 5 August 2014; Accepted 10 November 2014; Published 24 December 2014

Academic Editor: Xi Zhang

Copyright (c) 2014 F. I. Beltrán-Ramírez et al. This is an open access article distributed under the Creative Commons Attribution License, which permits unrestricted use, distribution, and reproduction in any medium, provided the original work is properly cited.

\begin{abstract}
The effect of nanometric magnesium and aluminum hydroxides on the flame retardancy of high density polyethylene was studied. Additionally, the effect of maleic anhydride grafted polyethylene (PEgMA) and methyl acrylate grafted polyethylene (EMA) compatibilizers, on the tensile properties, was also studied. Morphological characterization of nanocomposites was carried out by means of scanning transmission electron microscopy (STEM). Flame retardant properties of nanocomposites were evaluated by the UL-94 horizontal and vertical tests as well as by cone calorimeter tests. Thermal degradation behavior was analyzed with a thermogravimetric analyzer (TGA). Tensile tests were carried out according to ASTM D 638-03 in an Instron 4301 tensile testing machine. From STEM images, a good dispersion of flame retardants ( $\mathrm{MH}$ and $\mathrm{ATH}$ ) in the polymer matrix was observed, which was reflected in the flame retardant properties. Results showed that the combination of nanometric MH and ATH produced excellent flame retardant properties, achieving a classification of V0 in the UL-94-V test and producing the lowest peak of heat release rate (PHRR) and the lowest total heat released (THR) in the cone calorimeter test. Finally, the addition of compatibilizer, especially PEgMA, resulted in much better tensile properties as compared to the noncompatibilized composition, maintaining the flame retardant properties.
\end{abstract}

\section{Introduction}

Polyethylene (PE) is used in many different applications, due to its good all-around properties. Polyethylene, however, has a serious limitation when flame resistance is of importance in a given application. To overcome this limitation, flame retardants are added to the PE composition. After the highly efficient halogen-containing flame retardants have been banned, some fairly efficient halogen-free flame retardants are the hydrated metallic hydroxides [1-3].

Metallic hydroxide flame retardants comprise a large volume flame retardant group in the polymers market today. This group of products also presents no risk to human health or the environment and can therefore be labelled as environmentally friendly. These include aluminum hydroxide
(ATH), magnesium hydroxide $(\mathrm{MH})$, and a few other less common like magnesium-aluminium hydroxyl carbonates and certain other mixed metal hydroxides. However, ATH and $\mathrm{MH}$ together comprise most of the market volume of these flame retardants.

These metallic hydroxides reduce the flammability of polyethylene compositions, though high hydroxide content has to be used in order to attain acceptable flame retardancy. This high filler loading has a negative effect on several mechanical properties, turning the PE into a brittle and fragile composition with very poor tensile and impact properties.

ATH provides a flame retardant effect as it decomposes endothermically $(\Delta \mathrm{H}-280 \mathrm{cal} / \mathrm{g})$ [4] into aluminum oxide and water (about $35 \mathrm{wt} \%$ ). MH also decomposes endothermically $(\Delta \mathrm{H}-328 \mathrm{cal} / \mathrm{g})$ [4] into magnesium oxide 
TABLE 1: Compositions studied (all amounts are in phr; parts per hundred parts of resin).

\begin{tabular}{|c|c|c|c|c|c|c|}
\hline \multirow{2}{*}{ Compositions $^{\mathrm{a}, \mathrm{b}}$} & \multirow{2}{*}{ HDPE } & \multirow{2}{*}{ EPDM } & $\mathrm{MH}$ & ATH & $\mathrm{MH}$ & ATH \\
\hline & & & \multicolumn{2}{|c|}{$\mu \mathrm{m}$} & \multicolumn{2}{|c|}{$\mathrm{nm}$} \\
\hline M1 & 90 & 10 & - & - & 130 & - \\
\hline M2 & 90 & 10 & 32 & - & 98 & - \\
\hline M3 & 90 & 10 & 65 & - & 65 & - \\
\hline M4 & 90 & 10 & 98 & - & 32 & - \\
\hline M5 & 90 & 10 & 130 & - & - & - \\
\hline $\mathrm{A} 1$ & 90 & 10 & - & - & - & 130 \\
\hline $\mathrm{A} 2$ & 90 & 10 & - & 32 & - & 98 \\
\hline A3 & 90 & 10 & - & 65 & - & 65 \\
\hline A4 & 90 & 10 & - & 98 & - & 32 \\
\hline A5 & 90 & 10 & - & 130 & - & - \\
\hline MA2 & 90 & 10 & - & - & 98 & 32 \\
\hline MA3 & 90 & 10 & - & - & 65 & 65 \\
\hline MA4 & 90 & 10 & - & - & 32 & 98 \\
\hline
\end{tabular}

${ }^{a}$ All compositions contain $0.2 \mathrm{phr}$ silicon lubricant plus $0.15 \mathrm{phr}$ antioxidant.

${ }^{\mathrm{b}} \mathrm{M}$ compositions with micro- and nano-MH. A compositions with micro- and nano-ATH.

MA compositions with mix of nano-MH and nano-ATH.

and water (about $31 \mathrm{wt} \%$ ). These decomposition reactions absorb heat from the combustion zone, but, in addition, the resulting metallic oxide is left behind and provides a protective intumescent layer on the surface of the substrate. The decomposition temperature of ATH $[5,6]$ begins at ca. $240^{\circ} \mathrm{C}$, which may limit its application to polymers processed at relatively low temperatures, such as polyethylene, whereas $\mathrm{MH}$ begins to decompose at $320^{\circ} \mathrm{C}$ and allows its application to a much wider range of polymers.

To this end, there are a number of reports which consider the application of magnesium hydroxide nanoparticles as flame retardants in polymers [7, 8].

In 2003, at the ninth European Meeting on the Fire Retardancy of Polymeric Materials, several papers were focused on either micro- or nanomineral additives, such as aluminum hydroxide and magnesium hydroxide.

A comparison of Limiting Oxygen Index (LOI) and tensile strength (TS) data for EVA/MH composites, using microand nanosize $\mathrm{MH}$, showed that TS of the microcomposites decreased with increasing filler level, whereas it was almost unaffected on the nanocomposites $[9,10]$. LOI results for the nano-MH were also superior, especially at high filler levels. However, it should be noted that high nano-MH levels were still required to achieve reasonable resistance to ignition in common with more conventional, microsize, $\mathrm{MH}$ fillers. This negative effect on the mechanical properties is mainly due to the lack of interactions and/or compatibility between the highly nonpolar polymer matrix and the polar filler particles. One way to promote these interactions and/or compatibility is through the addition of a coupling agent, such as silanes [9], or, alternatively, through the addition of a compatibilizing agent, that is, a polymer combining the polar (hydrophilic) and nonpolar (hydrophobic) characteristics such as maleic anhydride grafted polyethylene (PEgMA) [1013] or copolymers of ethylene with butyl acrylate (EBA) or methyl acrylate (EMA) $[13,14]$.

It is the purpose of this work to study the effect of nanometric metallic hydroxides in combination with compatibilizing agents upon the fire retardancy and mechanical properties of polyethylene nanocompounds.

\section{Experimental}

2.1. Materials. Materials used were micrometric magnesium hydroxide $(\mathrm{MH})$ from Nuova Sima, Italy, with particle size of $2.4 \mu \mathrm{m}$, aluminum hydroxide (ATH) from Albemarle, USA, with particle size of $1.2 \mu \mathrm{m}$, and nanometric $\mathrm{MH}$ and ATH from Nanostructured \& Amorphous Materials, USA, with particle size of 20 and $50 \mathrm{~nm}$, respectively. A thermal stabilizer (BNX1035) and silicon oil (Wacker AK1000) were also used. The high density polyethylene (HDPE) used was from Dow Chemical, USA, with MFI of $0.7 \mathrm{~g} / 10 \mathrm{~min}$ (at $190^{\circ} \mathrm{C}$ with $2.16 \mathrm{~kg}$ ), density of $0.954 \mathrm{~g} / \mathrm{cm}^{3}$, and fusion temperature $\left(T_{m}\right)$ of $127^{\circ} \mathrm{C}$. The modified polyethylenes used as compatibilizers were from Arkema, USA, a maleic anhydride grafted polyethylene (PEgMA) with $2 \mathrm{wt} \%$ of maleic anhydride, with MFI of $3.5 \mathrm{~g} / 10 \mathrm{~min}$, and methyl acrylate grafted polyethylene (EMA) with $18 \mathrm{wt} \%$ methyl acrylate, with MFI of $2.5 \mathrm{~g} / 10 \mathrm{~min}$. For compound softness, an Ethylene-Propylene-Diene rubber (EPDM), from Lyondell, USA, with $70 \mathrm{wt} \%$ ethylene, with MFI of $0.6 \mathrm{~g} / 10 \mathrm{~min}$ was used.

2.2. Mixing and Sample Preparation. The formulations initially prepared are described in Table 1. Each composition was first mixed in a Henschel intensive powder mixer for $10 \mathrm{~min}$, 
TABLE 2: Flame resistance and tensile properties of compositions presented in Table 1.

\begin{tabular}{|c|c|c|c|c|c|}
\hline \multirow{2}{*}{ Formulations } & \multicolumn{2}{|c|}{ Flame resistance } & \multicolumn{3}{|c|}{ Tensile properties } \\
\hline & UL-94-V & UL-94-HB & Stress $[\mathrm{MPa}]$ & Elongation [\%] & Modulus [MPa] \\
\hline HDPE & Fails, drips & Fails & $16.0 \pm 1.0$ & $500 \pm 40$ & $340 \pm 35$ \\
\hline M1 & Fails, drips & $\mathrm{AE}^{\mathrm{c}}$ & $14.8 \pm 0.6$ & $50 \pm 5$ & $510 \pm 45$ \\
\hline M2 & Fails, drips & $\mathrm{AE}$ & $14.9 \pm 0.8$ & $40 \pm 5$ & $510 \pm 50$ \\
\hline M3 & Fails, drips & $\mathrm{AE}$ & $14.5 \pm 0.5$ & $50 \pm 4$ & $495 \pm 50$ \\
\hline M4 & Fails, drips & $\mathrm{AE}$ & $14.6 \pm 0.8$ & $40 \pm 4$ & $515 \pm 45$ \\
\hline M5 & Fails, drips & $\mathrm{AE}$ & $14.5 \pm 0.6$ & $50 \pm 5$ & $505 \pm 55$ \\
\hline $\mathrm{A} 1$ & Fails, drips & $\mathrm{AE}$ & $12.2 \pm 0.6$ & $50 \pm 6$ & $490 \pm 40$ \\
\hline A2 & Fails, drips & $\mathrm{AE}$ & $11.9 \pm 0.6$ & $40 \pm 5$ & $495 \pm 45$ \\
\hline A3 & Fails, drips & $\mathrm{AE}$ & $12.2 \pm 0.8$ & $40 \pm 5$ & $480 \pm 45$ \\
\hline A4 & Fails, drips & $\mathrm{AE}$ & $11.9 \pm 1.0$ & $40 \pm 4$ & $500 \pm 55$ \\
\hline A5 & Fails, drips & $\mathrm{AE}$ & $12.4 \pm 1.0$ & $40 \pm 4$ & $500 \pm 50$ \\
\hline MA2 & Fails, drips & $\mathrm{AE}$ & $14.9 \pm 1.0$ & $50 \pm 5$ & $500 \pm 50$ \\
\hline MA3 & V1 & $\mathrm{AE}$ & $14.2 \pm 0.8$ & $50 \pm 5$ & $505 \pm 45$ \\
\hline MA4 & Fails, drips & $\mathrm{AE}$ & $14.2 \pm 1.0$ & $50 \pm 4$ & $490 \pm 50$ \\
\hline
\end{tabular}

${ }^{\mathrm{c}}$ Autoextinguishable.

at $50^{\circ} \mathrm{C}$ and $1000 \mathrm{rpm}$. Thereafter, the dry mix was fed into a Werner ZSK30 corotating twin screw extruder with $L / D$ of 29 and $D$ of $30 \mathrm{~mm}$, at $100 \mathrm{rpm}$.

It should be noted that when avoiding the use of halogenated compounds, very high levels of flame retardant additive, such as $\mathrm{MH}$, are required to achieve reasonable fire resistance. This is the reason for using up to $130 \mathrm{phr}$ of flame resistance additive.

Compositions with $\mathrm{MH}$ were processed at $205^{\circ} \mathrm{C}$, whereas those with ATH were processed at $170^{\circ} \mathrm{C}$. Compositions with a mix of magnesium and aluminum hydroxides were processed at $170^{\circ} \mathrm{C}$. Immediately after extrusion, the materials were passed through a two-roll mill, at $150^{\circ} \mathrm{C}$ the ones with $\mathrm{MH}$ and at $135^{\circ} \mathrm{C}$ those with $\mathrm{ATH}$, to obtain small "bands" of each composition. Finally, the compositions were compression molded, at $190^{\circ} \mathrm{C}$ the ones with $\mathrm{MH}$ and at $170^{\circ} \mathrm{C}$ those with ATH, to obtain $125 \times 125 \times 3 \mathrm{~mm}$ laminates from which test specimens were cut.

2.3. Characterization. The UL 94 test is perhaps the most frequently used small flame burner test. It provides an assessment of flammability for a variety of thermoplastic materials intended for use in multiple applications. Performance is described through one of three ratings, V0, V1, or V2, depending on the number of seconds of after-flame burn time for each specimen, the total after-flame burn time for all specimens, the afterglow time, and the existence of flaming particles which may ignite a piece of cotton placed beneath the test specimens.

Flammability tests were performed according to UL-94, in both vertical $(94 \mathrm{~V})$ and horizontal $(94 \mathrm{HB})$ arrangements, on $125 \times 13 \times 3 \mathrm{~mm}$ specimens cut from compression molded laminates, which were previously conditioned for $48 \mathrm{~h}$ at $23^{\circ} \mathrm{C}$ and $50 \% \mathrm{RH}$.
Flammability tests were additionally performed on an FTT Dual Cone Calorimeter under a heat flux of $35 \mathrm{~kW} / \mathrm{m}^{2}$, in accordance with ASTM E1354, on $100 \times 100 \mathrm{~mm}$ specimens. Before testing, all specimens were conditioned for 24 hours at $23 \pm 3^{\circ} \mathrm{C}$ and $50 \pm 5 \% \mathrm{RH}$ and then wrapped with aluminum foil around the back and edges, to prevent molten material to drip over the load cell. The test samples were finally backed with a noncombustible insulating material and tested. All samples were run in triplicate.

Tensile tests were carried out according to ASTM D 63803 in an Instron 4301 tensile testing machine at a deformation rate of $5 \mathrm{~mm} / \mathrm{min}$.

Thermogravimetric analyses were performed in a TA Instruments TGA-951 between 30 and $600^{\circ} \mathrm{C}$, using a heating rate of $10^{\circ} \mathrm{C} / \mathrm{min}$, under a nitrogen flow of $50 \mathrm{~mL} / \mathrm{min}$.

The Melt Flow Index (MFI) tests for pure HDPE and HDPE composites were carried out at $190^{\circ} \mathrm{C}$, under a $2.16 \mathrm{~kg}$ weight, according to ASTM D1238.

Morphology and nanoparticle dispersion analyses were carried out with a JEOL JSM-7401 scanning electron microscope in transmission mode (STEM), on Au-Pd coated fractured samples from the previously obtained laminates. All samples were fractured at liquid nitrogen temperature. All micrographs were taken in COMPO mode in order to differentiate between polymer and filler. Finally, all samples were additionally examined through an EDAX attachment for a quantitative surface chemical analysis.

\section{Results and Discussion}

3.1. Flame Resistance and Tensile Properties. Table 2 presents the results of flame resistance and tensile properties of the compositions presented in Table 1. 


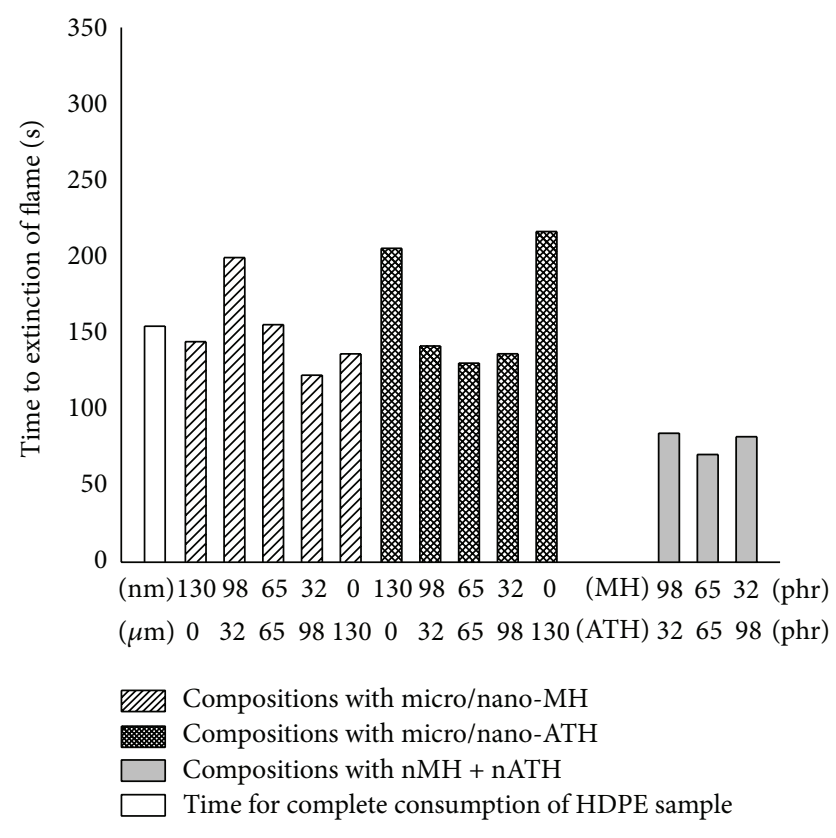

FIGURE 1: Time to self-extinction of flame during the UL-94-HB test of the compositions presented in Table 1. Note that all compositions contain $130 \mathrm{phr}$ of flame retardant filler.

With respect to flame resistance, it can be observed that all compositions passed the UL-94-HB standard as autoextinguishable (AE), whereas only the MA3 (with $65 \mathrm{phr}$ nano- $M H+65$ phr nano-ATH) passed the UL-94-V as V1; all others failed, showing slight to intense dripping. The HDPE sample was rapidly consumed completely.

In this sense, we believe that the nanohydroxides create a network throughout the polymer matrix that slows down the free pass of oxygen in smaller areas, by creating microand nanolabyrinths, retarding as a consequence the process of combustion.

In order to differentiate between the UL-94-HB results, where all compositions were classified as $\mathrm{AE}$, the time to self-extinction of flame was determined and the results are presented in Figure 1. It is observed that the times for the flame to extinguish itself varied from ca. $75 \pm 5 \mathrm{~s}$ for the compositions with a mix of nano-MH and nano-ATH (MA2, MA3, and MA4) to ca. $135 \pm 5 \mathrm{~s}$ for the compositions with a mix of micro- and nano-ATH (A2, A3, and A4), as well as for the compositions with a mix of micro- and nano-MH (M2, M3, and M4). Nevertheless, in none of these cases the flame advanced more than $3 \mathrm{~cm}$.

According to this, the compositions with the better flame resistance should be those that self-extinguish sooner, that is, the compositions with a combination of nano- $\mathrm{MH}$ and nano$\mathrm{ATH}$, followed by the compositions with a combination of micro- and nano-ATH or a combination of micro- and nano$\mathrm{MH}$. The one which self-extinguished in the shortest time was the one with $65 \mathrm{phr}$ nano-MH/65 phr nano-ATH (MA3), which is also the only one that was classified as V1 in the UL94-V test. With respect to tensile properties, the compositions

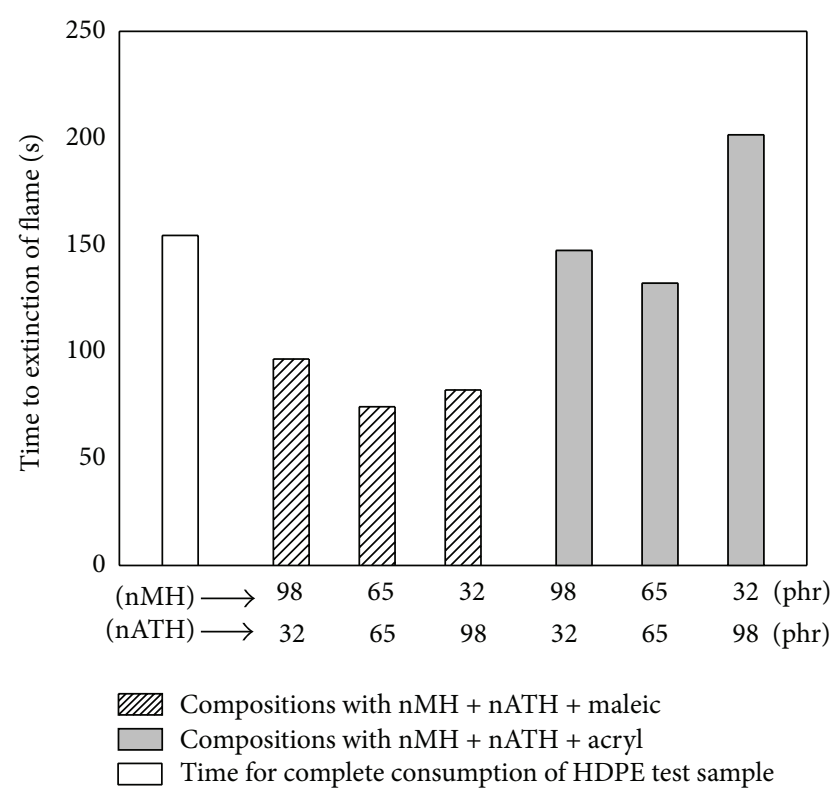

FIGURE 2: Time to self-extinction of flame during the UL-94-HB test of the compositions with compatibilizer, presented in Table 3.

TABLE 3: Compositions studied (continuation) (all amounts are in phr).

\begin{tabular}{lcccccc}
\hline Compositions $^{\text {a }}$ & HDPE & EPDM & PEgMA & EMA & $\begin{array}{c}\text { MH } \\
\text { nm }\end{array}$ \\
\hline MA2maleic & 80 & 10 & 10 & - & 98 & 32 \\
MA3maleic & 80 & 10 & 10 & - & 65 & 65 \\
MA4maleic & 80 & 10 & 10 & - & 32 & 98 \\
\hline MA2acryl & 80 & 10 & - & 10 & 98 & 32 \\
MA3acryl & 80 & 10 & - & 10 & 65 & 65 \\
MA4acryl & 80 & 10 & - & 10 & 32 & 98 \\
\hline
\end{tabular}

${ }^{a}$ All compositions contain $0.2 \mathrm{phr}$ silicon lubricant plus $0.15 \mathrm{phr}$ antioxidant. MA compositions with a mix of nano-MH and nano-ATH, with compatibilizer.

with micro- and nano-MH and the compositions with nano$\mathrm{MH}$ and nano-ATH present an average tensile stress (TS) of 14.7 and $14.4 \mathrm{MPa}$, respectively, which are in the same range of that of HDPE, whereas the compositions with microand nano-ATH present a lower average TS of $12.1 \mathrm{MPa}$. The elongation of all compositions, on the other hand, resulted much lower than that of HDPE. These results were attributed to the poor compatibility between polymer and filler, which was exacerbated by the high amount of filler.

Considering the above-mentioned results, two different compatibilizers (maleic anhydride grafted polyethylene (PEgMA) and methyl acrylate grafted polyethylene (EMA)) were added into compositions with a mix of nano-MH and nano-ATH (MA2, MA3, and MA4); the ones with the better flame resistance, substituting $10 \mathrm{phr}$ of HDPE with $10 \mathrm{phr}$ of compatibilizer, and the resulting compositions were analyzed. These are shown in Table 3. Figure 2 showsthe time 
TABLE 4: Flame resistance and tensile properties of compositions presented in Table 3.

\begin{tabular}{lccccc}
\hline \multirow{2}{*}{ Formulations } & \multicolumn{2}{c}{ Flame resistance } & & \multicolumn{2}{c}{ Tensile properties } \\
& UL-94-V & UL-94-HB & Stress [MPa] & Elongation [\%] & Modulus [MPa] \\
\hline HDPE & Fails, drips & fails & $16.0 \pm 1.0$ & $500 \pm 40$ & $340 \pm 35$ \\
\hline MA2maleic & Fails, drips & AE & $20.5 \pm 1.6$ & $200 \pm 15$ & $440 \pm 40$ \\
MA3maleic & V0 & AE & $20.7 \pm 1.6$ & $190 \pm 10$ & $430 \pm 35$ \\
MA4maleic & Fails, drips & AE & $19.9 \pm 2.0$ & $200 \pm 20$ & $445 \pm 35$ \\
\hline MA2acryl & Fails, drips & AE & $16.3 \pm 1.5$ & $150 \pm 15$ & $450 \pm 45$ \\
MA3acryl & V2 & AE & $16.7 \pm 1.2$ & $150 \pm 10$ & $440 \pm 45$ \\
MA4acryl & Fails, drips & AE & $15.8 \pm 1.5$ & $160 \pm 15$ & $440 \pm 40$ \\
\hline
\end{tabular}

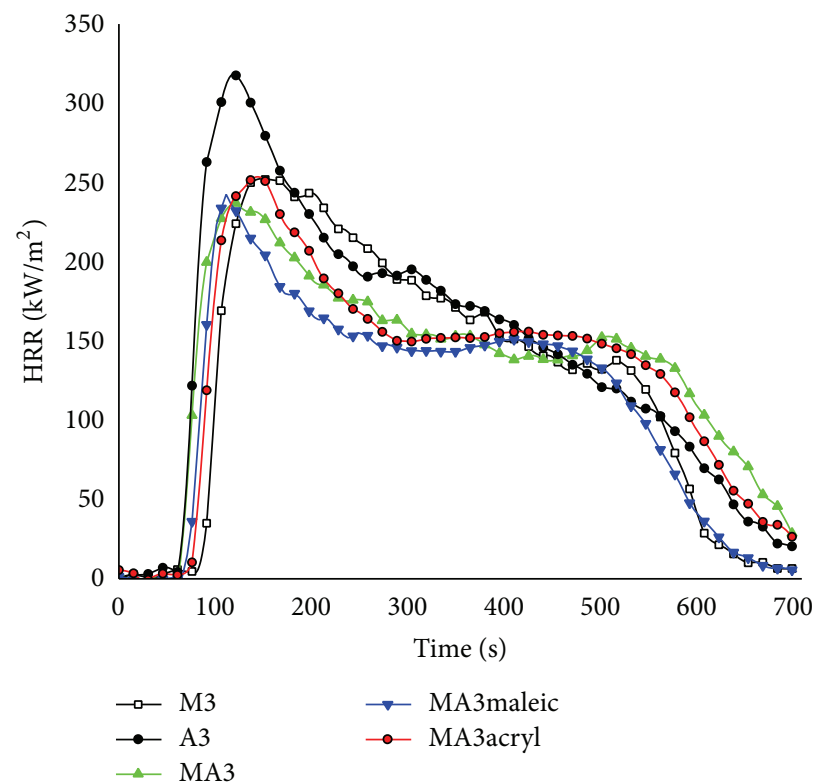

FIGURE 3: Heat release rate of compositions with 65 phr micro- and 65 phr nano-MH and 65 phr micro- and 65 phr nano-ATH (M3 and A3 from Table 1), as well as compositions with $65 \mathrm{phr}$ nano-MH/65 phr nano-ATH, without and with compatibilizer (MA3 from Table 1 and MA3maleic and MA3acryl from Table 3, resp.).

to self-extinction of flame during the UL-94-HB test of the compositions with compatibilizer, presented in Table 3.

Table 4 presents the flame resistance and tensile properties of the compositions with maleic or acrylate compatibilizer. Again, it can be observed that all six compositions passed the UL-94-HB standard as autoextinguishable (AE), and only the MA3maleic and the MA3acryl (with $65 \mathrm{phr}$ nano-MH/65 phr nano-ATH each), plus PEgMA or plus EMA, respectively, passed the UL- $94-\mathrm{V}$ as V0 and V2, respectively. All others failed, showing slight dripping. The tensile stress showed clearly the effect of compatibilizer, especially those with PEgMA, which reached an average TS of $20.4 \mathrm{MPa}$. The elongation of all six compatibilized compositions, on the other hand, resulted much higher than without compatibilizer ( $200 \%$ when using maleic compatibilizer and $\sim 150 \%$ when using acrylate compatibilizer), though still lower than that of pure HDPE.

First, the existence of van der Waals interactions between the HDPE and the PE of the PEgMA renders this blend of polyethylene and modified polyethylene compatible.
Additionally, the hydroxyl groups of the metallic hydroxides interact with the carbonyl groups of either the maleic anhydride or the methyl acrylate, via hydrogen bonding, increasing the compatibility between polymer and filler (Figure 4).

The heat release rate (HRR) is a measure of the rate of heat released to the surroundings per unit surface area of the burning material. Peak of heat release rate (PHRR) is the point of the highest rate of heat release. The higher the PHRR, the more likely the flame will self-propagate on the sample. The time to ignition is the time it took the sample to ignite after the test started. The time to PHRR is the time it took the sample to reach the PHRR. The total heat released (THR) is the total heat released since the time of ignition up to the time of flameout.

Heat release rate (HRR) has been found to be one of the most important parameters for evaluating material combustion and fire safety $[15,16]$.

Figure 3 shows the variation of HRR with time for HDPE as well as for the five selected compositions, as obtained from 
TABLE 5: Data obtained from the cone calorimeter: time to ignition, time to reach the PHRR, heat release rate at the peak (PHRR), total heat released (THR) since ignition to flameout, and time to flameout.

\begin{tabular}{|c|c|c|c|c|c|}
\hline & Time to ignition [s] & Time to peak HRR [s] & Peak HRR $\left[(\mathrm{kJ} / \mathrm{s}) / \mathrm{m}^{2}\right]$ & THR $\left[\mathrm{MJ} / \mathrm{m}^{2}\right]$ & Time to flameout [s] \\
\hline HDPE & 63 & 150 & 2030.11 & 110.58 & 178 \\
\hline M3 & 86 & 155 & 255.35 & 86.71 & 593 \\
\hline A3 & 65 & 125 & 257.75 & 93.64 & 710 \\
\hline MA3 & 67 & 120 & 265.29 & 99.91 & 709 \\
\hline MA3maleic & 76 & 125 & 240.44 & 79.61 & 597 \\
\hline MA3acryl & 80 & 125 & 256.63 & 87.53 & 681 \\
\hline
\end{tabular}

Note: $1 \mathrm{~W}=1 \mathrm{~J} / \mathrm{s}$.

Data for HDPE was also obtained experimentally, though it is not shown in Figure 3.

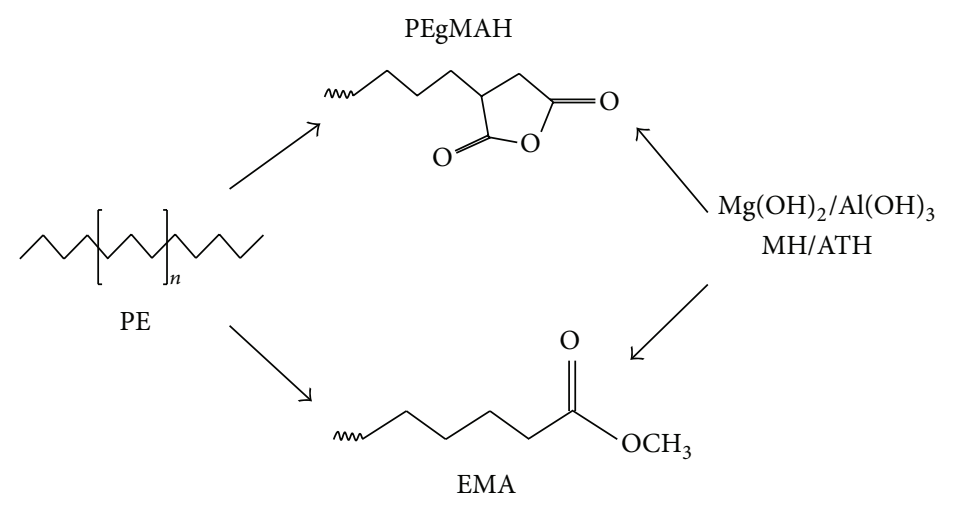

FIGURE 4: Hydrogen bond interactions between the hydroxyl groups of the metallic hydroxides and the carbonyl groups of either the maleic anhydride or the methyl acrylate.

the cone calorimeter analysis, and Table 5 shows the data obtained from the cone calorimeter, such as time to ignition, time to reach the PHRR, maximum HRR, and total heat released (THR) during the experiment, for HDPE as well as for the five selected flame resistant compositions examined.

First, it is observed that the HRR at the peak of the flame resistant compositions is ca. 8 times less than that of pure HDPE. Moreover, the time to flameout of pure HDPE is around 3.5-4.0 times less than that of the flame resistant compositions; that is, $\mathrm{PE}$ releases a great amount of heat $\left(110 \mathrm{MJ} / \mathrm{m}^{2}\right)$ in a very short period of time (178 s).

Second, though smaller, there is still a noticeable difference among the flame resistance compositions. The best allaround being the one designated as MA3maleic, with $65 \mathrm{phr}$ nano-MH/65 phr nano-ATH, with PEgMA as compatibilizer (lowest PHRR and lowest THR).

This can be assumed to be due to the nanometric size of the flame retardant fillers and also due to the increased compatibility between polymer and filler, brought about by the PEgMA [10].

These results, which point to the MA3maleic as the best among the studied compositions, coincide with those obtained above with the UL-94-HB and UL-94-V tests.
3.2. Thermogravimetric Analysis (TGA). Figure 5 shows the TGA thermograms of $\mathrm{MH}, \mathrm{ATH}, \mathrm{HDPE}$ and the compositions with $65 \mathrm{phr}$ nano-MH/65 phr nano-ATH, without compatibilizer (MA3) and with compatibilizer (MA3maleic and MA3acryl), which were the only ones that passed the UL94-V.

First, it can be observed that the $\mathrm{MH}$ presents a weight loss of ca. $28 \mathrm{wt} \%$ between 350 and $440^{\circ} \mathrm{C}$ due to decomposition and liberation of water vapor, leaving approximately $72 \mathrm{wt} \%$ of magnesium oxide as residue. ATH presents a weight loss of ca. $34 \mathrm{wt} \%$ between 230 and $320^{\circ} \mathrm{C}$ due also to decomposition and liberation of water vapor, leaving approximately $66 \mathrm{wt} \%$ of aluminum oxide as residue.

Pure HDPE, on the other hand, decomposes and volatilizes between 380 and $490^{\circ} \mathrm{C}$, leaving almost no residue.

It is important to point out that, according to the TGA results, the metallic hydroxides remained intact during processing, since the TGA thermograms of the prepared compositions coincide with the TGA thermograms of the individual fillers.

In the case of the $65 \mathrm{phr} \mathrm{MH} / 65 \mathrm{phr}$ ATH nanocomposites, without compatibilizer and with PEgMA and EMA compatibilizer (MA3, MA3maleic, and MA3acryl), they present 


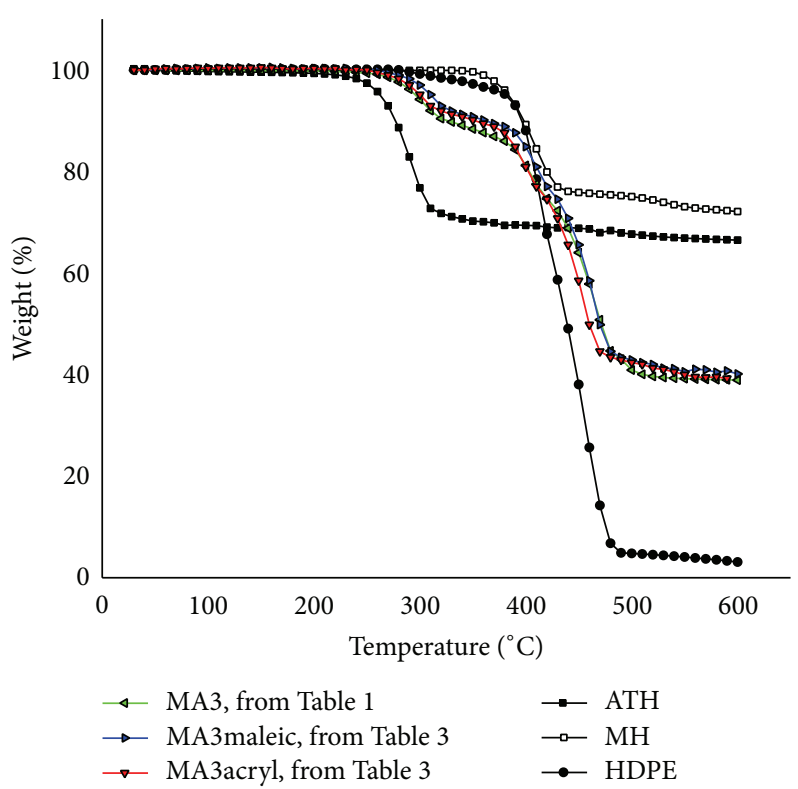

FIGURE 5: TGA thermograms of the MH and ATH hydroxides, HDPE and the compositions with 65 phr nMH/65 phr nATH, without and with compatibilizer (MA3 from Table 1 and MA3maleic and MA3acryl from Table 3).

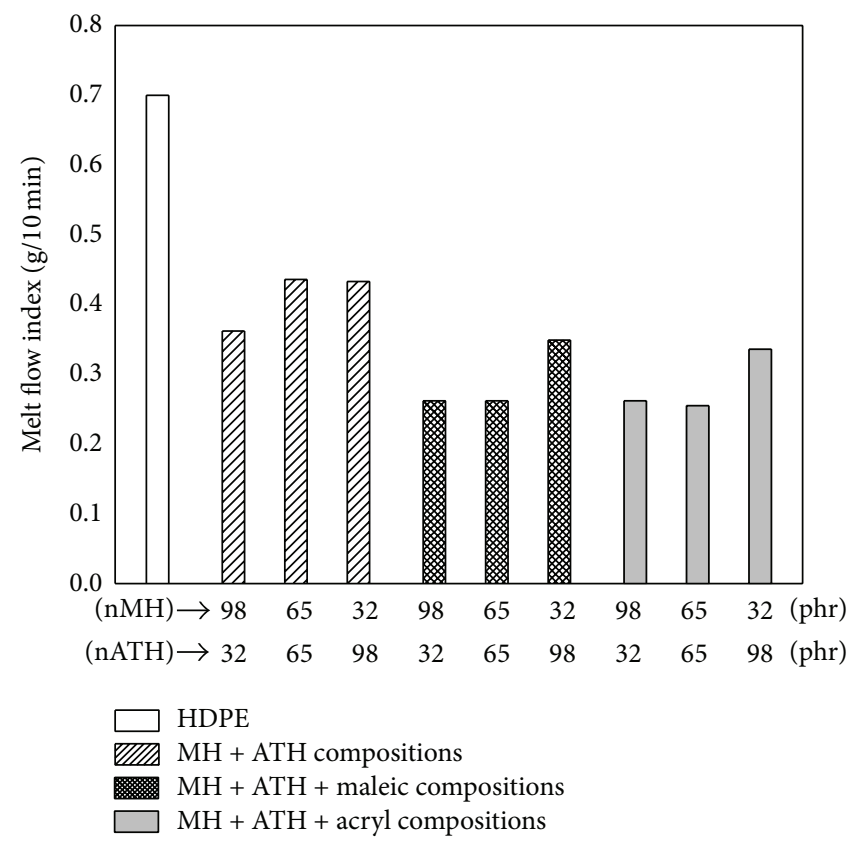

FIGURE 6: MFI of the 65 phr nano-MH/65 phr nano-ATH containing compositions, without compatibilizing agent and with maleic anhydride and methyl acrylate modified polyethylenes as compatibilizer.

very similar curves which superimpose each other. The three nanocomposites present the signals due to decomposition of ATH and liberation of water vapor between 280 and $320^{\circ} \mathrm{C}$, and thereafter, due to decomposition of $\mathrm{MH}$ and liberation of water vapor between 380 and $420^{\circ} \mathrm{C}$. Finally, the nanocomposites show another weight loss between 400 and $490^{\circ} \mathrm{C}$ due to the decomposition and volatilization of polyethylene and modified polyethylene, leaving approximately $38 \mathrm{wt} \%$ of aluminum and magnesium oxides as residue.
3.3. Melt Flow Index. Figure 6 presents the melt flow index of the nanometric $\mathrm{Mg}$ and $\mathrm{Al}$ hydroxide containing compositions, without compatibilizer and with maleic anhydride and methyl acrylate modified PE as compatibilizers.

First, as compared to that of pure HDPE, the MFI decreases with the addition of the metallic hydroxide fillers, as should have been expected. Second, comparing the compositions with metallic hydroxides, it is observed that (a) the MFI of the compositions with compatibilizer appears negligibly 


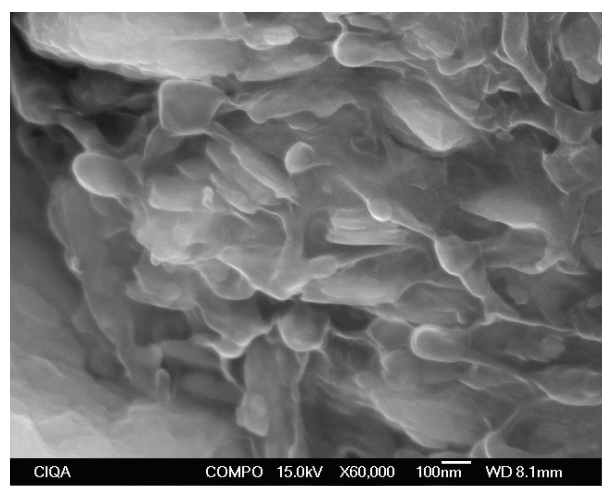

(a)

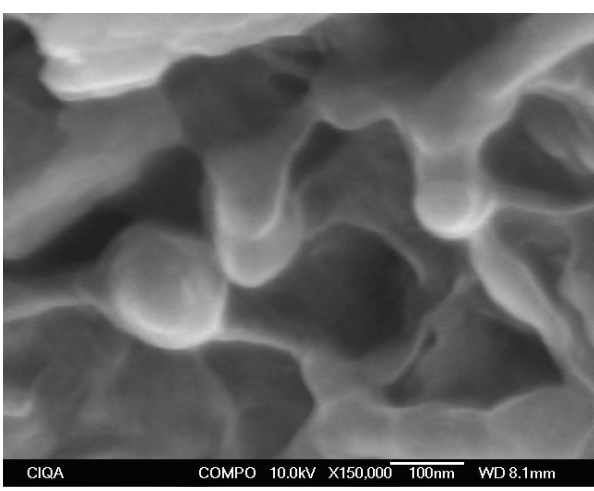

(b)
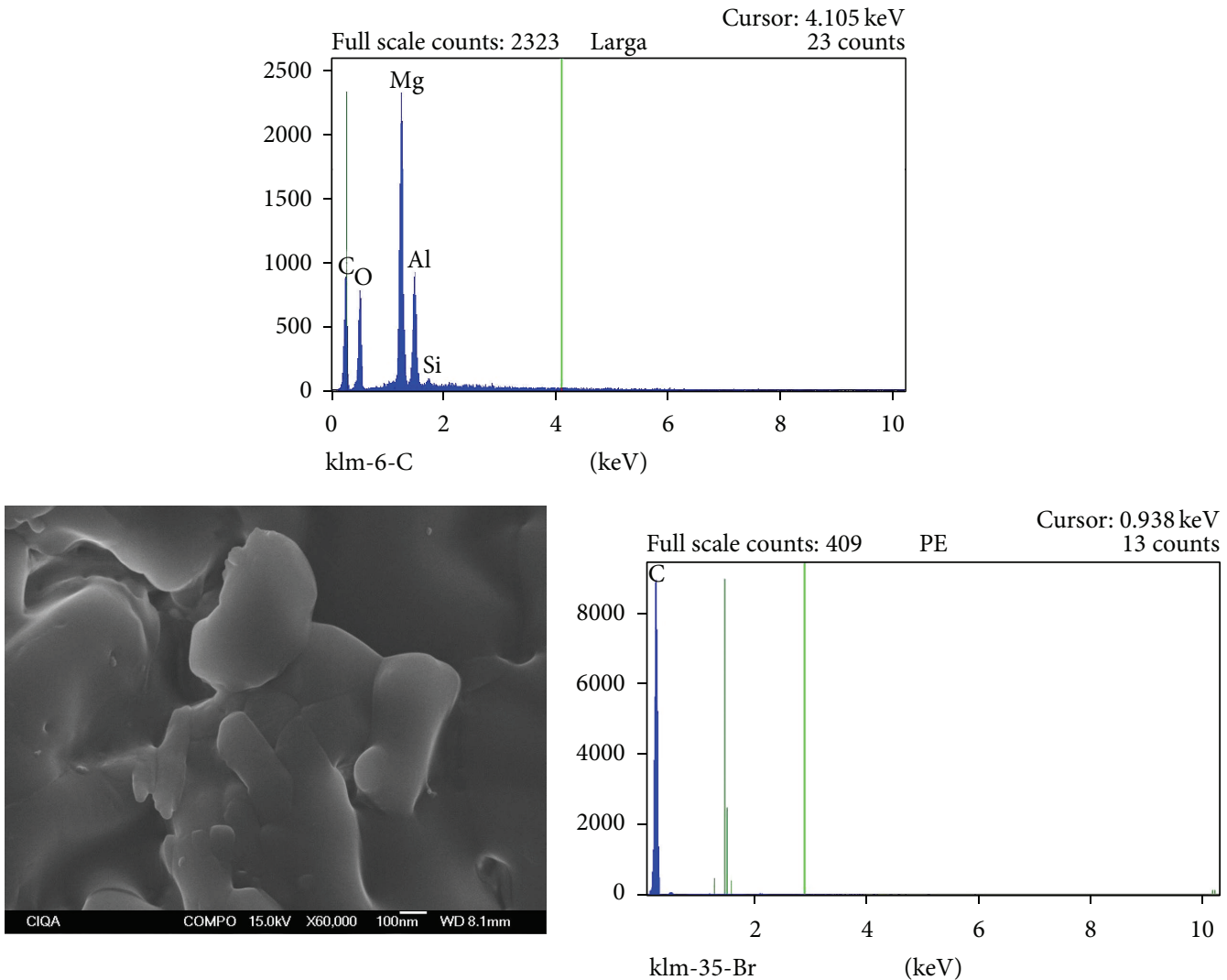

(c)

FIGURE 7: STEM micrographs of the $65 \mathrm{phr}$ nano-MH/65 phr nano-ATH composite, without compatibilizer (MA3), at (a) 60,000x and (b) 150,000x, with their corresponding EDAX quantitative chemical analysis, as well as a micrograph of pure polyethylene (c), at 60,000x, with their corresponding chemical analysis.

lower and (b) there is no difference with respect to the effect of the two different compatibilizers.

3.4. Morphological Characterization. Figures 7(a) and 7(b) show STEM micrographs of the $65 \mathrm{phr} \mathrm{MH} / 65 \mathrm{phr}$ ATH nanocomposite, without compatibilizer (Figures 7(a) and 7(b); sample MA3), where agglomerates of filler particles are observed, which surely contributed to the very low tensile elongation; nonetheless, this morphology was sufficient for the MA3 composition to pass the UL-94-V test as V1.
In addition, Figure 7(c) shows a STEM micrograph of the pure polyethylene, where very smooth zones, without filler, are observed. Figures 7(a) and 7(b) present an EDAX chemical analysis showing the presence of both magnesium and aluminum hydroxides, whereas Figure 7 (c) presents an EDAX analysis showing only the presence of carbon.

Figures $8(\mathrm{a})$ and $8(\mathrm{~b})$ show STEM micrographs of the 65 phr nano-MH/65 phr nano-ATH composite, with PEgMA as compatibilizer (sample MA3maleic), where some particle agglomerates are still observed. However, in comparison 


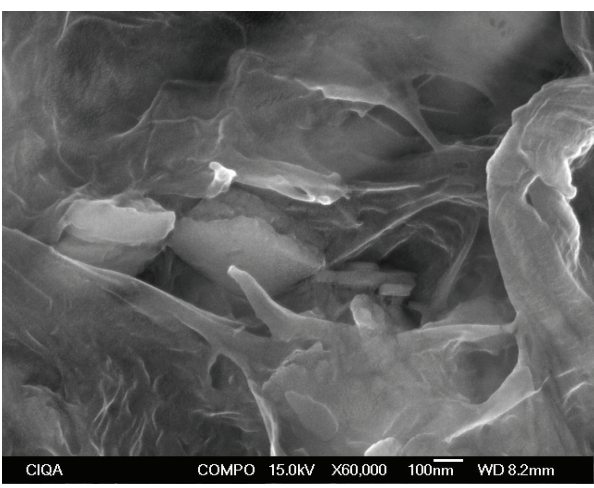

(a)

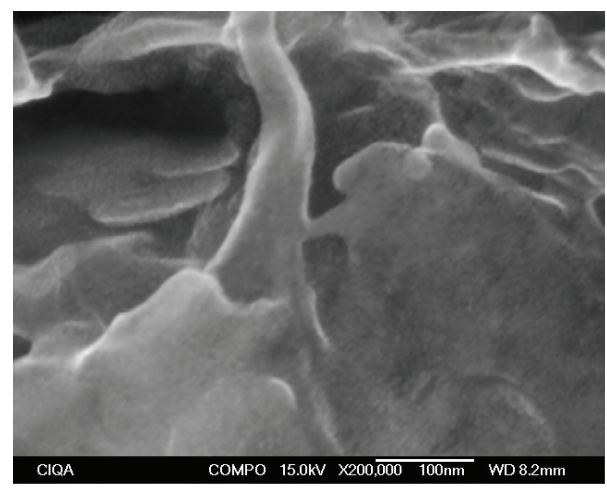

(b)

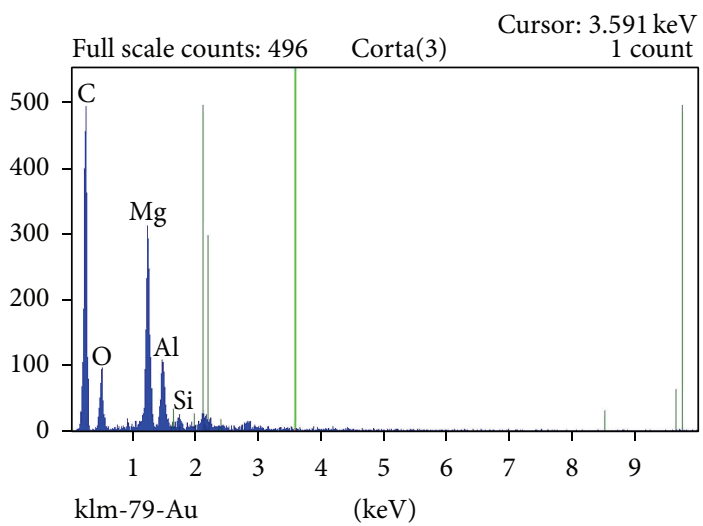

FIGURE 8: STEM micrographs of the MA3maleic composition, at (a) 60,000x and (b) 200,000x, with their corresponding EDAX quantitative chemical analysis.

with the similar composition, without compatibilizer (sample MA3), the filler particles now appear completely wetted by the polymer, surely due to the effect of compatibilizer. This effect contributed to a markedly greater TS and a slightly greater elongation of the MA3maleic composition. In addition, this MA3maleic passed the UL-94-V test as V0. An EDAX chemical analysis showed the presence of both magnesium and aluminum metallic hydroxides.

Figures 9(a) and 9(b) show STEM micrographs of the $65 \mathrm{phr}$ nano-MH/65 phr nano-ATH composite, with EMA as compatibilizer (sample MA3acryl). Again, some agglomerates of filler particles are still observed. However, the filler particles appear completely wetted by the polymer. The presence of agglomerates, however, appears slightly greater when using this acrylate compatibilizer than when using the maleic compatibilizer.

The greatest TS (ca. $20 \mathrm{MPa}$ ) with moderate elongations (ca. 200\%) were achieved with the composites with $65 \mathrm{phr}$ nano-MH/65 phr nano-ATH, with PEgMA as compatibilizer.

An EDAX chemical analysis showed the presence of both magnesium and aluminum hydroxides. The EDAX elemental analysis showed that when the analysis is directed to the dispersed nanometric particles, the concentration of magnesium appears markedly superior to that of aluminum. On the contrary, when the analysis is directed towards the agglomerates, the concentration of aluminum is superior.
This leads to the assumption that, under these conditions, the ATH nanoparticles have a greater tendency to agglomerate than the MH nanoparticles.

\section{Conclusions}

All compositions studied throughout this work passed the UL-94-HB. All showed to be autoextinguishable, though the time to the self-extinction of flame varied.

The best compositions were those with a mix of nanometric magnesium and aluminum hydroxide. In addition, the composition with $65 \mathrm{phr} n \mathrm{nH}+65 \mathrm{phr}$ nATH (MA3) was the only one that passed the UL-94-V as V1. Nonetheless, the tensile properties of all these highly filled compositions were very poor, especially the elongation.

When adding a compatibilizer, maleic anhydride or methyl acrylate modified polyethylene, these compositions again passed the UL-94-HB. Moreover, these compositions (with $65 \mathrm{phr} \mathrm{nMH}+65 \mathrm{phr}$ nATH, with PEgMA or EMA) passed the UL-94-V as V0 and V2, respectively. But more noticeable, the effect of compatibilizer showed up in the tensile properties. The compositions with PEgMA reached an average tensile stress of $20.4 \mathrm{MPa}$, higher than that of pure HDPE, and an average elongation of $200 \%$, lower than that of pure HDPE, but markedly higher than the compositions without compatibilizer. 


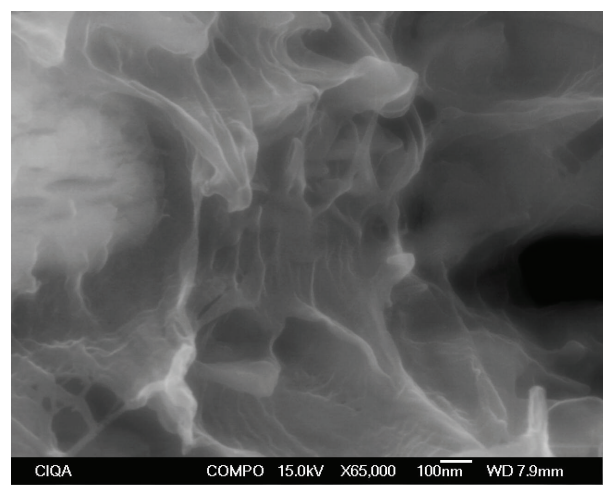

(a)

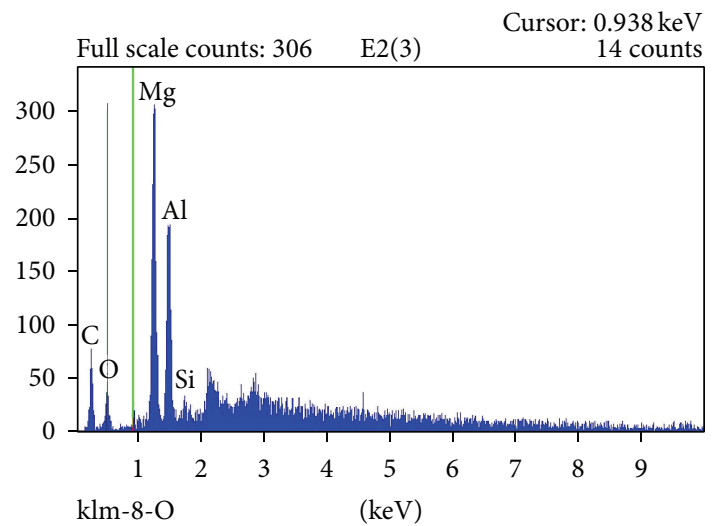

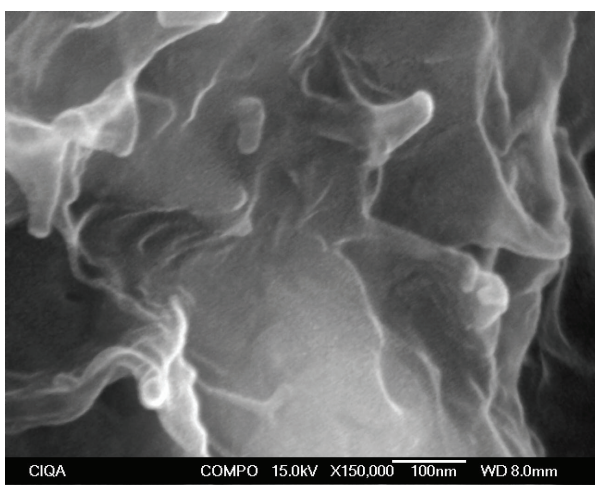

(b)

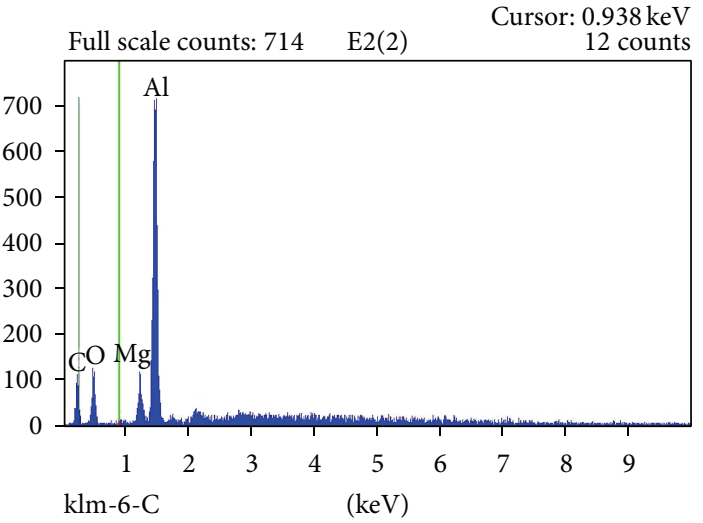

FIGURE 9: STEM micrographs of the MA3acryl composition, at (a) 65,000x and (b) 150,000x, with their corresponding EDAX quantitative chemical analysis.

Corroborating the results presented above, the cone calorimeter tests results showed the composition with $65 \mathrm{phr}$ $\mathrm{nMH}+65 \mathrm{phr} \mathrm{nATH}$, with PEgMA as compatibilizer, to be the best among the studied compositions, with the lowest peak of HRR and THR.

Via STEM, it was observed that noncompatibilized samples showed many agglomerates, whereas the compatibilized samples showed much less agglomerates and, additionally, the filler particles now appeared completely wetted by the polymer, surely due to the effect of compatibilizer, especially the maleic anhydride modified polyethylene.

Finally, a punctual EDAX analysis showed that the aluminum concentration was always higher on the agglomerates, leading to the conclusion that the ATH presents a higher tendency to agglomerate than the $\mathrm{MH}$.

\section{Conflict of Interests}

The authors declare that there is no conflict of interests regarding the publication of this paper.

\section{Acknowledgments}

Two of the authors (F. I. Beltrán-Ramírez and E. N. CabreraAlvarez) thank CONACYT for granting them scholarships to carry their $\mathrm{PhD}$ studies. Also, the authors gratefully acknowledge the financial support of CONACyT through projects CB-222805 and LN-232753. The authors also wish to thank M. Sanchez Adame, Francisco Zendejo, Mario Palacios, Rodrigo Cedillo, Jesus Rodriguez, Luis Enrique Reyes, Alejandro Espinoza, Sergio Zertuche, Fabian Chavez, Adán Herrera, E. Hurtado Suarez, and D. Alvarado for their technical and informatics support.

\section{References}

[1] F. Carpentier, S. Bourbigot, M. Le Bras, R. Delobel, and M. Foulon, "Charring of fire retarded ethylene vinyl acetate copolymer-magnesium hydroxide/zinc borate formulations," Polymer Degradation and Stability, vol. 69, no. 1, pp. 83-92, 2000.

[2] Z. Wang, B. Qu, W. Fan, and P. Huang, "Combustion characteristics of halogen-free flame-retarded polyethylene containing magnesium hydroxide and some synergists," Journal of Applied Polymer Science, vol. 81, no. 1, pp. 206-214, 2001.

[3] Z. Li and B. Qu, "Flammability characterization and synergistic effects of expandable graphite with magnesium hydroxide in halogen-free flame-retardant EVA blends," Polymer Degradation and Stability, vol. 81, no. 3, pp. 401-408, 2003.

[4] M. D. Walter and M. T. Wajer, Overview of Flame Retardants, Martin Marietta Magnesia Specialties, Baltimore, Md, USA, 1998.

[5] G. Camino, A. Maffezzoli, M. Braglia, M. de Lazzaro, and M. Zammarano, "Effect of hydroxides and hydroxycarbonate 
structure on fire retardant effectiveness and mechanical properties in ethylene-vinyl acetate copolymer," Polymer Degradation and Stability, vol. 74, no. 3, pp. 457-464, 2001.

[6] K. McGarry, J. Zilberman, R. Hull, and W. D. Woolley, "Decomposition and combustion of EVA and LDPE alone and when fire retarded with ATH," Polymer International, vol. 49, no. 10, pp. 1193-1198, 2000.

[7] L. Qiu, J. Lu, R. Xie, and B. Qu, "Structural characteristics and flame-retardant properties of nanosized magnesium hydroxide," Chinese Journal of Semiconductors, vol. 24, pp. 81-84, 2003.

[8] F. Laoutid, L. Bonnaud, M. Alexandre, J.-M. Lopez-Cuesta, and P. Dubois, "New prospects in flame retardant polymer materials: From fundamentals to nanocomposites," Materials Science and Engineering R: Reports, vol. 63, no. 3, pp. 100-125, 2009.

[9] E. N. Cabrera-Álvarez, L. F. Ramos-Devalle, S. Sánchez-Valdes et al., "Study of the silane modification of magnesium hydroxide and their effects on the flame retardant and tensile properties of high density polyethylene nanocomposites," Polymer Composites, vol. 35, no. 6, pp. 1060-1069, 2014.

[10] N. Wang, J. Zhang, Q. Fang, and D. Hui, "Influence of mesoporous fillers with PPgMA on flammability and tensile behavior of polypropylene composites," Composites B: Engineering, vol. 44, no. 1, pp. 467-471, 2013.

[11] S. M. B. Nachtigall, M. Miotto, E. E. Schneider, R. S. Mauler, and M. M. Camargo Forte, "Macromolecular coupling agents for flame retardant materials," European Polymer Journal, vol. 42, no. 5, pp. 990-999, 2006.

[12] U. Hippi, J. Mattila, M. Korhonen, and J. Seppälä, "Compatibilization of polyethylene/aluminum hydroxide (PE/ATH) and polyethylene/magnesium hydroxide $(\mathrm{PE} / \mathrm{MH})$ composites with functionalized polyethylenes," Polymer, vol. 44, no. 4, pp. 11931201, 2003.

[13] R. Lujan-Acosta, S. Sánchez-Valdes, E. Ramírez-Vargas et al., "Effect of amino alcohol functionalized polyethylene as compatibilizer for LDPE/EVA/clay/flame-retardant nanocomposites," Materials Chemistry and Physics, vol. 146, no. 3, pp. 437-445, 2014.

[14] L. Zhang, C. Z. Li, Q. Zhou, and W. Shao, "Aluminum hydroxide filled ethylene vinyl acetate (EVA) composites: effect of the interfacial compatibilizer and the particle size," Journal of Materials Science, vol. 42, no. 12, pp. 4227-4232, 2007.

[15] M. Zanetti, T. Kashiwagi, L. Falqui, and G. Camino, "Cone calorimeter combustion and gasification studies of polymer layered silicate nanocomposites," Chemistry of Materials, vol. 14, no. 2, pp. 881-887, 2002.

[16] M. Zanetti, G. Camino, R. Thomann, and R. Mülhaupt, "Synthesis and thermal behaviour of layered silicate-EVA nanocomposites," Polymer, vol. 42, no. 10, pp. 4501-4507, 2001. 

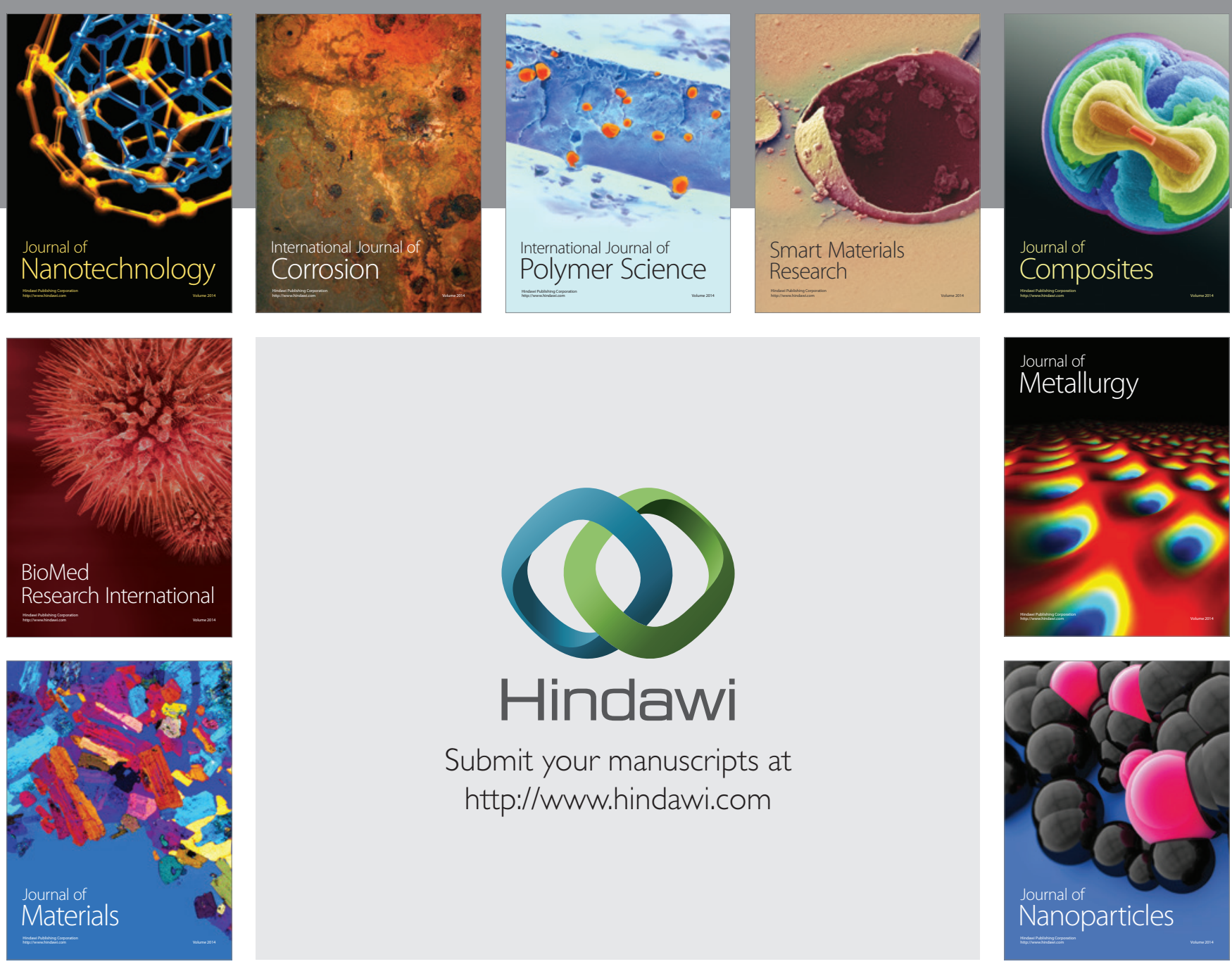

Submit your manuscripts at http://www.hindawi.com
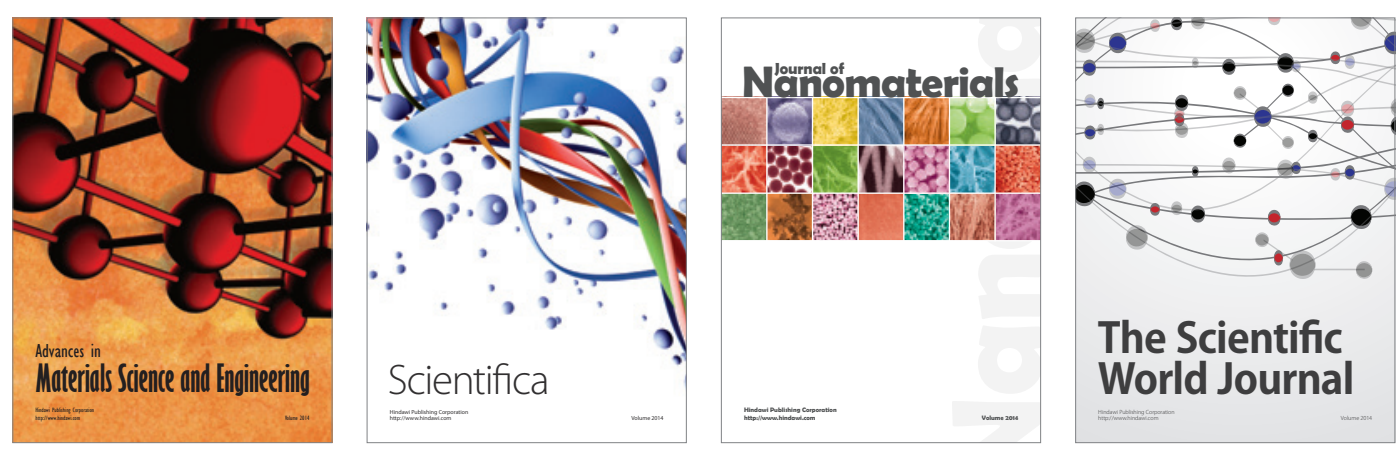

\section{The Scientific World Journal}
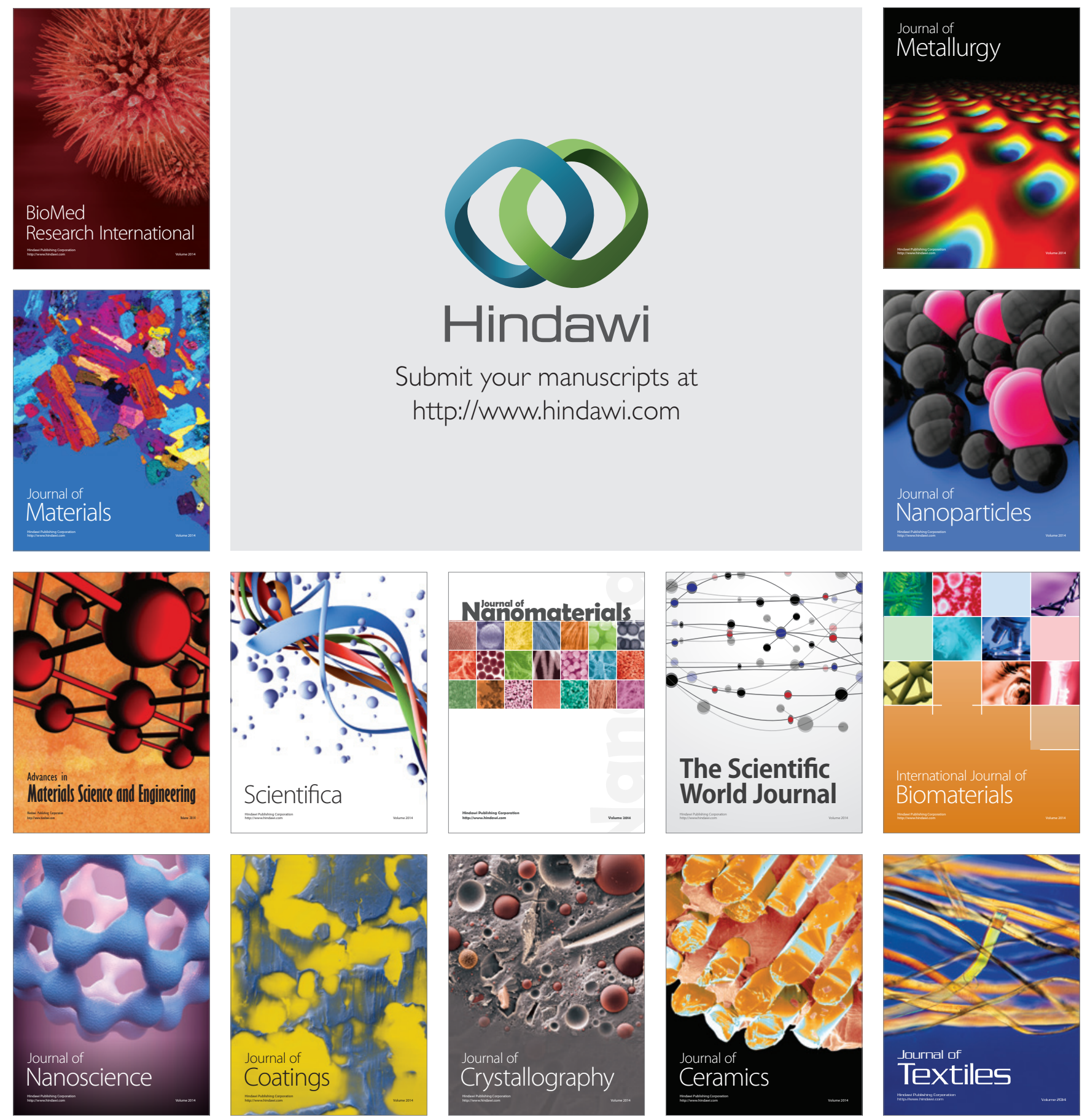